\title{
La izquierda estudiantil de la Universidad de Buenos Aires en la transición democrática (1982-1985)
}

\author{
Yann Cristal y Guadalupe A. Seia \\ UBA - Conicet-UBA \\ ycristal@yahoo.com; guadalupeseia@gmail.com
}

\section{Introducción}

Este trabajo busca contribuir a la investigación de un período singular y poco examinado de la historia del movimiento estudiantil argentino, como es el de la década de 1980. En particular, indagamos aquí el desarrollo de las agrupaciones estudiantiles de izquierda de la Universidad de Buenos Aires (UBA) en la llamada transición democrática. ${ }^{1}$ Por un lado, analizamos su papel en la reorganización de los centros de estudiantes y en las movilizaciones universitarias de esos años. Por otro, consideramos las dificultades que enfrentaron en el complejo escenario de los 80 , caracterizado por fuertes cambios políticos, entre los que se destacan la nueva hegemonía de Franja Morada sobre el movimiento estudiantil porteño y la relativa pérdida de influencia de la izquierda.

Nos concentramos en el lapso que va desde mediados de 1982 a finales de 1985. Este período aborda el ciclo de auge de la movilización juvenil y estudiantil que se abrió con la crisis de la dictadura tras la Guerra de Malvinas, en medio de una renovada conflictividad social y el inicio de la apertura política que desembocaría en la elección de Raúl Alfonsín como presidente. Son los años de la "primavera democrática", marcados por el optimismo de la mayor parte de los estudiantes con la democracia, al tiempo que nuevas tensiones fueron emergiendo a partir de las políticas del gobierno radical. En este sentido, el lapso estudiado contiene dos momentos diferenciados: por un lado, los últimos dos años de la dictadura y, por otro, el primer bienio del gobierno de Alfonsín, con elementos que continúan y otros que mutan. Situamos el cierre de nuestro trabajo a fines de 1985, momento que coincide en la UBA con la clausura del proceso de normalización.

1. Para una problematización del concepto de "transición democrática" ver Cecilia Lesgart (2002: 163-185).

(Archivos, año VI, $\mathrm{n}^{\circ}$ 12, marzo de 2018, pp. 97-118) 
Dentro del movimiento estudiantil de los años 80, en este artículo nos concentramos en las agrupaciones estudiantiles de izquierda, que han sido poco investigadas en comparación con los trabajos existentes sobre Franja Morada (FM en adelante), brazo universitario del radicalismo (Altamirano, 1987; Polak y Gorbier, 1994; Muiño, 2011; Beltrán, 2013). Diversos escritos recientes han buscado reponer una mirada más abarcativa sobre el conjunto de la militancia universitaria y juvenil del periodo (Seia, 2015, 2016; Luciani, 2017; Cristal, 2015, 2017; Blanco y Vommaro, 2017; Manzano, 2017), pero aún resta investigar el conjunto de las experiencias políticas estudiantiles de la etapa. En este sentido, entendemos que las agrupaciones de izquierda jugaron un papel relevante en el proceso de reconstrucción de los centros de estudiantes y de rearticulación de la movilización del estudiantado, a pesar de no lograr un apoyo mayoritario en las primeras elecciones de centros. Más aún, analizar este contraste entre su sostenida militancia y su magro resultado electoral, así como el avance de fuerzas de izquierda "nuevas" como el Partido Intransigente (PI) o las llamadas agrupaciones independientes, podría contribuir a una caracterización más compleja sobre el movimiento estudiantil a la salida de la última dictadura.

Es preciso aclarar que consideraremos en un sentido amplio a la izquierda estudiantil universitaria. De este modo, incluimos a las agrupaciones de tendencia trotskista (Partido Socialista de los Trabajadores/ Movimiento al Socialismo, PST/MAS; Partido Obrero, PO), maoísta (Partido Comunista Revolucionario, PCR), comunista (Partido Comunista, $\mathrm{PC})$, y también a las denominadas agrupaciones "independientes de izquierda" de la UBA y a la Juventud Universitaria Intransigente (JUI), alineada dentro del PI. Asimismo, excluimos del foco de análisis a los agrupamientos identificados con los partidos politicos nacionales mayoritarios (Unión Cívica Radical y Partido Justicialista). Se trata de una elección metodológica, en la medida en que dentro del radicalismo y el peronismo existieron en los 80 corrientes autodenominadas de izquierda. Sin embargo, consideramos interesante indagar aquí el recorrido de los partidos y agrupaciones antes mencionados, que nos permite acercarnos a los distintos significados y posicionamientos que adoptó la izquierda estudiantil durante los años investigados. ${ }^{2}$

2. Tampoco abordamos en este artículo al MNR y otras expresiones estudiantiles vinculadas al socialismo, que podrian caracterizarse como de "centroizquierda", en virtud de su relación más cercana con FM y su proyección acotada dentro del período estudiado. Excluimos también a fuerzas de izquierda con un alcance menor como las de la Izquierda Nacional - FIP, o Praxis de Filosofia y Letras y Sociología. Por otra parte, al no concentrarnos en el radicalismo y el peronismo tampoco ahondaremos en sus líneas internas durante el período. Cabe no obstante mencionarlas. Dentro de FM existieron en los 80 dos sectores principales: el de la Junta Coordinadora Nacional 
Por último, este artículo pretende aportar en tres campos de estudio. En primer lugar, la historia del movimiento estudiantil argentino contemporáneo, cuyos trabajos se concentran mayormente en el lapso que va de la Reforma del 18 a las grandes movilizaciones estudiantiles de $\operatorname{los} 60$ y 70 . Considerando que en los 80 se abrió un periodo ininterrumpido de funcionamiento legal de los centros de estudiantes que se prolonga hasta la actualidad, el estudio sobre el movimiento estudiantil de la posdictadura podría colaborar en la comprensión del desarrollo de las organizaciones estudiantiles hasta el presente. En segundo lugar, buscamos contribuir a la historia de las izquierdas en la Argentina, investigando un período significativo y poco indagado. En tercer lugar, este trabajo intenta aportar elementos para la comprensión más general de la historia reciente de nuestro país, en particular los procesos y conflictos políticos y sociales que marcaron la salida de la dictadura y los inicios de la actual democracia en la Argentina.

\section{Un movimiento estudiantil que se pone de pie (1982-1983)}

El movimiento estudiantil universitario, y en particular las agrupaciones de izquierda, fueron víctimas de la prohibición de sus actividades, la ilegalización de sus estructuras y la represión a sus militantes, en diversos grados y con diferencias regionales. A través del decreto 6 de la Junta de Gobierno se suspendió la actividad política y los partidos políticos con jurisdicción nacional, provincial, municipal, y se ilegalizó a numerosos partidos como Política Obrera, Partido Socialista de los Trabajadores, Partido Comunista Revolucionario y Vanguardia Comunista (Casola, 2015). En junio de 1976 la ley 21.322 disolvía o declaraba ilegales a un importante número de agrupaciones políticas, sindicales y estudiantiles, marxistas y peronistas. ${ }^{3}$

En paralelo, la ley 21.276 estableció la vigencia de la prohibición en

(JCN), mayoritario en casi todas las facultades y alineado dentro del alfonsinismo, y el de la Corriente Nacional y Popular (CNP), más crítico de Alfonsín. Por su parte, dentro de la JUP se fueron delineando dos alas: la "JUP Capital", vinculada al peronismo renovador de Antonio Cafiero, y la "JUP Regional", ligada a ex dirigentes de Montoneros y a la corriente Intransigencia y Movilización.

3. Entre ellas, la Federación Juvenil Comunista (FJC-PC), el Movimiento de Orientación Reformista (MOR-PC), la Unión de Estudiantes Secundarios (UES-JP), Corriente Universitaria por la Revolución Socialista (CURS), Tendencia Estudiantil Revolucionaria por el Socialismo (TERS-PO), Juventud Guevarista (JG), Juventud Universitaria Peronista (JUP), Juventudes Políticas Argentinas, Frente de Agrupaciones Universitarias de Izquierda (FAUDI), Juventud Universitaria Socialista de Avanzada (JUSA), Agrupación Universitaria Nacional (AUN), Frente Estudiantil Nacional (FEN). 
las universidades nacionales de "toda actividad que asuma formas de adoctrinamiento, propaganda, proselitismo o agitación de carácter político o gremial, docente, estudiantil o no docente" que constaba en la ley universitaria aprobada en marzo de 1974 bajo el gobierno constitucional de Perón (Buchbinder, 2014; Friedemann, 2016). Para hacer cumplir dicha normativa se instalaron de forma permanente en los claustros agentes de la Policía Federal.

La militancia estudiantil fue objeto de la política represiva del autodenominado "Proceso de Reorganización Nacional": cientos de estudiantes, no docentes y docentes fueron secuestrados, desaparecidos y/o asesinados. Asimismo, se impuso una politica de achicamiento de la matrícula estudiantil y el reordenamiento de la estructura universitaria constituyendo una institución jerárquica en su interior y subordinada respecto del Poder Ejecutivo Nacional (PEN), opuesta a la tradición reformista (Seia, 2017).

A pesar de la represión generalizada, algunos grupos de estudiantes politizados continuaron en contacto, sosteniendo reuniones periódicas y clandestinas (Pedrosa, 2002; Perel et al., 2006). Dos fenómenos tempranos, que aparecen entre 1978 y 1979 , merecen ser resaltados debido a su importancia posterior para la rearticulación de la militancia. Por un lado, las revistas estudiantiles, impulsadas principalmente por militantes pertenecientes a la FJC que generaron espacios de socialización y discusión estudiantil ajenos al control de las autoridades. Por otro, las comisiones para la reconstrucción de los centros de estudiantes impulsadas por diferentes tendencias estudiantiles según la facultad, donde se destacaron las corrientes de izquierda trotskistas y comunistas (Seia, 2016). ${ }^{4}$

\section{Las primeras movilizaciones}

En el contexto de relativa apertura política a partir de la presidencia de facto de Roberto Viola (Canelo, 2009), las agrupaciones estudiantiles realizaron sus primeras acciones públicas en las facultades y una movilización callejera. El 22 de octubre de 1981, la clandestina Federación Universitaria de Buenos Aires (FUBA) convocó una marcha hacia el Palacio Pizzurno, sede del Ministerio de Cultura y Educación, con la finalidad de entregar a las autoridades un petitorio contra el arancelamiento de los estudios de grado, que había sido autorizado por la reciente ley universitaria 22.207 y puesto en marcha ese año en

Vale aclarar que el PCA fue suspendido al igual que los partidos peronista, radical, socialista, etc., no ilegalizado.

4. Según las fuentes analizadas, existieron esas comisiones en las facultades de Derecho, Filosofia y Letras, Psicología, Agronomía, Ingeniería, Ciencias Económicas. 
la UBA. Asistieron algunos cientos de personas y el evento finalizó con una fuerte represión. ${ }^{5}$

La organización del movimiento estudiantil dio un salto a partir de la Guerra de Malvinas de 1982. El estado general de conmoción social posibilitó la localización de mesas por parte de los diferentes agrupamientos estudiantiles en los pasillos y bares de las facultades, aunque en principio no se identificaron como tales, sino como estudiantes en apoyo a los combatientes. Con el final del enfrentamiento bélico y la agudización de la crisis de la dictadura, las agrupaciones ya no se retiraron de la actividad pública en las sedes de la UBA a pesar de la permanencia policial.

A fines de 1982 se organizaron las primeras asambleas en las facultades y a inicios de 1983 se produjo un estallido estudiantil contra los cupos al ingreso y el examen eliminatorio, con masivas movilizaciones, que expresaban en simultáneo un repudio más general a la dictadura militar y a su politica universitaria en particular. ${ }^{6}$ Junto a las restricciones al ingreso, los estudiantes cuestionaban el arancelamiento a los estudios de grado, como se manifestó en la quema en la vía pública de las chequeras con las que debía abonarse el arancel, la normalización en base a la ley 22.207 y la realización de concursos docentes fraudulentos, denunciados como "maniobra continuista" (Seia, 2017).

En relación a las leyes universitarias, existia acuerdo entre las agrupaciones estudiantiles sobre la anulación de la ley 22.207. En cambio, se planteó un intenso debate respecto de la normativa que debía aplicarse en su lugar. Los jóvenes comunistas e intransigentes, junto con peronistas y radicales, sostenían que debía entrar en vigencia la última normativa universitaria sancionada bajo un gobierno democrático: la ley 20.654 de 1974. En cambio, los sectores trotskistas (UJS, MAS) y maoístas (FAUDI) se oponían a ese posicionamiento argumentando que la ley 20.654 posibilitaba la intervención en las universidades nacionales por el PEN, prohibía la actividad política en las facultades, restringia la participación estudiantil en el co-gobierno, disponía la designación de las autoridades por el PEN e implantaba exámenes de ingreso.

5. La Nación, "Grave incidente en un acto estudiantil", 23 de octubre de 1981, y "La Policía informó sobre la agresión a un fotógrafo", 24 de octubre de 1981; Revista Interacción, año III, $\mathrm{n}^{\circ} 7,1981$. Cf. Seia (2016).

6. Clarin, "La FUBA convoca a los aspirantes", 6 de marzo de 1983; "Masiva solicitud de los aspirantes al ingreso", 11 de marzo de 1983; "Marcha de protesta estudiantil", 23 de marzo de 1983; La Voz, "El ingreso irrestricto es el reclamo del estudiantado", 6 de marzo de 1983; La Nación, "Aspirantes al ingreso en la UBA realizaron una marcha", 11 de marzo de 1983; Tiempo Argentino, "Se cumplió la marcha de protesta estudiantil", 11 de marzo de 1983; "Crece la agitación en la universidad", 23 de marzo de 1983. 
En simultáneo, en las movilizaciones de 1982 y 1983 los universitarios confluyeron con organizaciones como las Madres de Plaza de Mayo y exigieron la aparición con vida de los estudiantes detenidos-desaparecidos y la legalización de la actividad política estudiantil. Una nueva agenda de reclamos por los Derechos Humanos se expresó en los primeros murales y banderas con los nombres de los desaparecidos en varias facultades.

En todas estas manifestaciones, el espectro de agrupaciones participantes era amplio, incluyendo radicales, socialistas, peronistas, comunistas, trotskistas, maoístas, intransigentes, e independientes. Las diversas fuerzas de izquierda participaron activamente e incluso formaron parte de las delegaciones que ingresaron al Ministerio para presentar los reclamos formalmente ante las autoridades. ${ }^{7}$

Indudablemente, la izquierda había sufrido fuertemente las consecuencias de la represión con fuerzas enteras aniquiladas como el PRT o Vanguardia Comunista y otras con gran cantidad de asesinados y desaparecidos. No obstante, en el marco de la apertura política y en el camino que llevaria a las elecciones presidenciales de 1983 se produjo un auge de la militancia en partidos políticos y agrupaciones universitarias, con miles de estudiantes participando e incluso afiliándose. Aunque la Juventud Radical fue quizá la organización juvenil partidaria que más creció durante la campaña electoral del 83, todas las agrupaciones experimentaron un crecimiento. La FJC, que habia mantenido un status semilegal durante la dictadura, era una de las fuerzas más numerosas de la UBA, con decenas de militantes en facultades como Ciencias Exactas y Naturales, donde contaba con 13 círculos. ${ }^{8}$ Por su parte, el MAS tenía agrupaciones importantes en varias facultades y carreras (Psicologia, Filosofia y Letras, entre otras), mientras que el PI crecía en las facultades humanísticas. El PO y el PCR, con un alcance

7. En las movilizaciones de marzo de 1983 ingresaron al ministerio dirigentes de FM, MAS, MOR, JUP, JUI e independientes de izquierda (ver notas periodísticas antes citadas).

8. FJC, Cuadernos Universitarios, abril de 1983; Comité Central del Partido Comunista, Desbaratar la maniobra del continuismo reaccionario en la universidad, 9 de septiembre de 1982. Gilbert (2009: 671-674) destaca el crecimiento numérico de afiliados y activistas en las filas de la Fede hacia el final de la dictadura. Sostiene que en las movilizaciones callejeras luego de la guerra de Malvinas, las columnas más voluminosas eran la de la juventud radical y la comunista. Argumenta esta situación con la "actitud más persistente" de la FJC en la lucha por reivindicaciones y en el mantenimiento de vínculos con las mesas juveniles. Vale interrogarse, siguiendo a Casola (2015), si dicho crecimiento de las organizaciones del PCA durante la dictadura no se debió también a que ofrecían un espacio donde militar bajo un esquema que garantizaba a los jóvenes alguna "protección y/o seguridad" frente al aparato represivo dada la situación legal del partido. 
algo menor, también tenían presencia en varias facultades. Finalmente, entre las agrupaciones independientes de izquierda, el MTU de Filosofia y Letras realizaba plenarios de no menos de 30 personas en $1983 .{ }^{9}$

La fuerza militante de los distintos espacios de la izquierda, sumada a su presencia en las movilizaciones y comisiones reorganizadoras y al clima de unidad antidictatorial, expresaban una aparente paridad entre las distintas fuerzas políticas. Es decir, no era tan clara aún una ventaja relativa para el radicalismo dentro de las facultades. No obstante, las elecciones de centros de estudiantes de 1982 y 1983 manifestaron una correlación de fuerzas bastante diferente.

\section{La reorganización de los centros}

Desde mediados de 1982, las comisiones pro-centro y las agrupaciones comenzaron a convocar asambleas por facultad para discutir los pasos a seguir para la conformación de los centros y la convocatoria a comicios estudiantiles. Las asambleas contaron con una notable participación de cientos de estudiantes. ${ }^{10}$ Además de definir el calendario electoral, las asambleas exigian la devolución de los bienes de los centros y la liberalización de la actividad política.

A fines de 1982, se realizaron los primeros comicios en Exactas, Psicología e Ingenieria. ${ }^{11} \mathrm{FM}$ triunfó en las tres facultades (Tabla 1). El resultado fue sorpresivo en cada caso, pero los comunistas destacaron la decepcionante derrota de la lista presentada por su agrupación en Exactas ${ }^{12}$ ya que en dicha facultad habian sido la última conducción electa antes del golpe de estado de $1976,{ }^{13}$ habian mantenido una importante actividad, impulsaban las revistas estudiantiles en las carreras de Física, Matemática, Biología y Química y poseían una trayectoria de militancia histórica en esa casa de estudios. En cambio, los radicales sólo contaban con dos militantes activos en dicha facultad. ${ }^{14}$

9. Entrevista a Vivian Scheinsohn (MTU), realizada por el autor, 2017.

10. Para una contabilidad detallada de asambleas estudiantiles entre 1982 y 1983 , ver Cristal (2017).

11. Diferencias entre las agrupaciones, e incluso entre las distintas líneas internas de FM, generaron que en 1982 se realizaran sólo estas tres elecciones y recién en 1983 las del resto de las facultades.

12. FM logró 855 votos. En segundo lugar quedó la lista independiente de izquierda AEI (604 votos) y luego la Lista Unidad impulsada por el MOR-PC (507 votos). Los trotskistas obtuvieron 99 votos entre las dos listas ( $L a$ Voz, 21 de noviembre de 1982).

13. En 1975, en una elección clandestina con una urna "flotante", el MOR-FJC obtuvo 597 votos, la JUP 439 y la alianza TERS-JSA 290.

14. FJC, Cuadernos Universitarios, abril de 1983. Gilbert (2009: 679). Pablo Mauas 
Tabla 1: Conducciones de centros de estudiantes de la UBA, elecciones $1982-1983^{15}$

\begin{tabular}{|l|c|c|}
\hline Centro & 1982 & 1983 \\
\hline Agronomía & - & LAI (Ind. der.) \\
\hline Arquitectura & - & FM \\
\hline Ciencias Económicas & - & FM \\
\hline Ciencias Exactas y Naturales & FM & FM \\
\hline Derecho & - & FM \\
\hline Farmacia y Bioquímica & - & Lista Ind. (der.) \\
\hline Filosofía y Letras & - & FM \\
\hline Ingeniería & FM & FM \\
\hline Medicina & - & FM \\
\hline Odontología & - & EIFO (Ind.) \\
\hline Psicología & FM & JUI \\
\hline Sociología & - & JUI \\
\hline Veterinaria & - & FM \\
\hline
\end{tabular}

Durante 1983, los resultados confirmaron la tendencia del año anterior: FM ratificó su dominio sobre el movimiento estudiantil de la UBA. Por detrás de FM se ubicaron los "independientes de derecha" que lograron la conducción de tres centros y la JUI que ganó dos (Tabla 1). También realizaron una buena elección los "independientes de izquierda" nucleados en el BUIT (Bloque Universitario Independiente para la Transformación).

Los testimonios de quienes militaron en esa época expresaron la sorpresa que les causó el triunfo de FM incluso en facultades donde dicha agrupación había tenido una escasa militancia en comparación con otras organizaciones, como ocurrió en Filosofia y Letras. ${ }^{16}$ En esa facultad, el frente JUP-JUI era candidato al triunfo y se pensaba que algunas fuerzas de izquierda (MOR-FJC, PST-MAS, UJS-PO), que habian sostenido cierto nivel de actividad durante toda la etapa y habian militado

recuerda que Juan Pablo Paz (candidato a presidente por la Lista Unidad) había concurrido al escrutinio con sus padres porque esperaban una victoria segura (entrevista por la autora, 2015).

15. Las tablas del presente artículo son elaboración propia de los autores a partir de datos recolectados en diversas fuentes periodisticas (diarios Clarín, La Nación y La Voz). La Tabla 2 incluye información de la Base de Datos de Pablo Bonavena sobre el movimiento estudiantil de los 60 y 70 . Los datos completos de las elecciones de 1982 y 1983 pueden consultarse en Cristal (2015).

16. Entrevistas realizadas a Daniel Sierra, Patricio Geli, Lucas Luchilo, Pablo Alabarces, entre otros, por la autora, 2015. 
desde el principio las comisiones pro-centro, tendrian un desempeño electoral superior al de FM. ${ }^{17}$ En este sentido, en algunas facultades se manifestaba una contradicción entre el arrasador caudal de votos del radicalismo y una cantidad de militantes escasa en comparación con las distintas fuerzas de izquierda, aun cuando durante 1983 la afiliación a la Juventud Radical había sido muy significativa a nivel general.

Varios medios de prensa destacaron el cambio politico que expresaban los resultados electorales en relación a las agrupaciones estudiantiles que habian hegemonizado el movimiento estudiantil en las décadas precedentes. ${ }^{18}$ Efectivamente, una comparación con las elecciones de centros realizadas en 1973 da cuenta de una duplicación de los votos radicales, una caída apabullante del peronismo y una fuerte pérdida de influencia del PC y el FAUDI (Tabla 2). También cayó el trotskismo, más aún si se considera que había crecido hacia $1975 .^{19}$

Los planteos con los que FM ganó las elecciones de 1983 iban en sintonía con los ejes planteados por Alfonsín en su campaña electoral (Aboy Carlés, 2001). Tenían como núcleo la crítica a la "violencia del pasado" (término que incluía tanto al terrorismo de Estado como a la izquierda revolucionaria, en el marco de la "teoría de los dos demonios")

17. Entrevistado pocas semanas antes por Clarín (9 de mayo de 1983), Eduardo Martínez, dirigente de la UJS, planteaba en relación a dicha elección: "Tenemos posibilidades verdaderas de ganar". No obstante, la lista unitaria del MAS y la UJS terminó en quinto lugar, detrás de FM, FUNAP (JUI-JUP), MTU (independiente de izquierda) y MAPU (FJC e independientes). En el caso de la FJC debería incorporarse como variable para explicar su magro desempeño electoral en la UBA el desprestigio que generó el apoyo del PC a Videla desde 1976 y su propuesta de "convergencia cívico-militar" durante los años más duros de la dictadura (Casola, 2015).

18. Por ejemplo, La Nación (10 de noviembre de 1982) señaló que "el resultado de esos comicios indica una crisis de los grupos de ultraizquierda (maoístas y trotskistas)", mientras que Clarin (19 de junio de 1983) se preguntaba " $¿ H a$ nacido una nueva forma de hacer politica en la Universidad?", y sostenía lisa y llanamente: "Los estudiantes afirman que ha terminado el tiempo de la virulencia partidista y que ahora pueden militar en un clima serio y adulto".

19. Las últimas elecciones de centros de la UBA antes del golpe se realizaron en 1975, pero de forma clandestina, sólo en algunas de las facultades y con una participación estudiantil menor. Por ese motivo comparamos los comicios de 1983 con las últimas votaciones masivas y legales realizadas en 1973. Cabe aclarar que los guarismos que logró el peronismo en 1973 son relativamente excepcionales en comparación con los años previos donde agrupaciones como el MOR o el FAUDI habian tenido una incidencia mayor. A la vez, a partir de 1974, en el marco de la llamada "misión Ivanissevich" y de la fuerte persecución al movimiento estudiantil, ya comenzaron a manifestarse cambios en la correlación de fuerzas de los centros de estudiantes. Franja Morada logró entonces un crecimiento de su influencia (Millán, 2015). 
Tabla 2: Total de votos en elecciones de centros UBA, años 1973 y 1983

\begin{tabular}{|l|c|c|}
\hline Agrupación & $\mathbf{1 9 7 3}$ & $\mathbf{1 9 8 3}$ \\
\hline FM-UCR $^{*}$ & $20,9 \%$ & $40,3 \%$ \\
\hline JUP-PJ & $40,8 \%$ & $6,6 \%$ \\
\hline MOR/FJC-PC & $17,5 \%$ & $5,7 \%$ \\
\hline FAUDI-PCR & $7,8 \%$ ** & $0,3 \%$ \\
\hline TERS/UJS-PO & $3,1 \%$ & $1,0 \%$ \\
\hline PST-MAS & $1,9 \%$ & $2,0 \%$ \\
\hline
\end{tabular}

* Incluye las distintas ramas de Franja. En 1973 tenía más peso la Juventud Radical Revolucionaria (JRR) y en 1983, la Junta Coordinadora Nacional (JCN).

${ }^{\star *}$ Frente FAUDI-TUPAC (agrupación ligada a Vanguardia Comunista)

y un nuevo ideal, la democracia, como camino y como meta. ${ }^{20}$ Es indudable que dentro de las ideas predominantes entre los estudiantes universitarios del 83, la consolidación de la democracia fue un eje estructurante de nuevos valores y sentidos, lo que constituye un cambio significativo con respecto a las décadas de los 60 y 70 .

A la vez, podrian pensarse ciertas continuidades. De algún modo, el ascenso del peronismo en la UBA en 1973 ya había representado un momento dificil para la izquierda estudiantil no peronista. Tanto el 73 como el 83 encontraron a muchas fuerzas de izquierda intentando ir más allá del consenso mayoritario que en cada caso expresó uno de los dos partidos políticos hegemónicos. Por otra parte, como analizó Marina Franco (2015: 45), la "teoría de los dos demonios" tenía fuerte raigambre en una matriz que se remonta al período 1973-1976 en cuanto al componente binario, la equiparación de responsabilidades y el origen de la violencia, luego resignificada y potenciada por el alfonsinismo. Finalmente, encontramos en las agrupaciones estudiantiles de los 80 consignas antiimperialistas que parecen asociadas a las décadas previas. Incluso FM planteaba en 1983 la lucha por la "liberación nacional y

20. Oscar Riva, dirigente de FM de Ciencias Económicas, sostenía: "Hasta el año 74 , los grupos de ultraizquierda que habian entrado en la facultad como centro de reclutamiento ideológico desvirtuaron las verdaderas funciones de los centros de estudiantes $[\ldots]$ luego se inició una reacción que llevó al otro extremo, [...] ahora es necesaria una organización seria y responsable, una conducción que represente al estudiante medio" (Clarín, 28 de noviembre de 1982). 
social", ${ }^{21}$ aunque aclarando que tal objetivo se conseguiria por el camino de la consolidación de la democracia.

En el marco de esta complejidad y combinación de elementos, una parte de las fuerzas de izquierda de los 80 tomó distancia del movimiento estudiantil de los 60 y 70. Por ejemplo, un referente del PI reivindicaba "una serie de nuevos valores que habian ido naciendo a lo largo de los años de la dictadura, y que tenían que ver con un respeto mucho mayor por las relaciones democráticas", 22 mientras un dirigente del MOR afirmaba que "el lado positivo es la mayor madurez que ganamos tan dolorosamente [...] nos dimos cuenta de que no queremos repetir las manifestaciones violentas del movimiento estudiantil". ${ }^{23}$ Estas fuerzas fueron parte de las impulsoras del MOJUPO (Movimiento de las Juventudes Políticas), brazo juvenil de la Multipartidaria, que reunía entre otras a las juventudes de la UCR, el PJ, el PI y el PC. A nivel estudiantil, la confluencia se plasmó en el primer congreso de la FUBA en 1983 con la conformación de la "Lista de Unidad Nacional" entre FM, JUP, JUI, MOR, MNR y hasta UPAU, ${ }^{24}$ que ungió a Andrés Delich (FM) como presidente. ${ }^{25}$ Expresando el clima de unidad y la absorción de ciertas consignas antiimperialistas dentro del nuevo clima de ideas imperantes, el cántico emblema de ese Congreso fue: "Radicales de Yrigoyen / peronistas de Perón / comunistas, intransigentes / para la liberación". ${ }^{26}$ De este modo, la "lucha por la liberación" se integraba con "el repudio a todo tipo de violencia como método de acción política", como señalaba el documento fundacional del MOJUPO. ${ }^{27}$

Aquí encontramos entonces una de las dificultades para la izquierda de los 80. Tras años de dictadura, no sólo se expresaba una correlación de fuerzas desfavorable en las elecciones estudiantiles, sino que las ideas de FM se imponían a partir del contraste con el movimiento estu-

21. Por ejemplo, en el primer congreso de la FUBA, Andrés Delich de FM declaró: "El enemigo aún acecha, pero los estudiantes de todos modos vamos a estar junto al pueblo para conquistar la liberación nacional y social de nuestra patria" ( $L a$ Voz, 6 de noviembre de 1983).

22. Julián Gadano, dirigente del PI, citado en Toer (1988: 222).

23. Buenos Aires Herald, 17 de junio de 1983. En inglés en la publicación original, traducción de los autores del artículo.

24. Unión para la Apertura Universitaria, agrupación liberal vinculada a la Ucedé.

25. Quedaron afuera del frente, criticándolo, las agrupaciones independientes, el trotskismo y el maoísmo, en clara minoría.

26. La Prensa, "La federación universitaria local eligió sus autoridades", 7 de noviembre de 1983; La Voz, "Quedó normalizada la FUBA", 6 de noviembre de 1983.

27. "Un documento de todos y para todos", Aqui y ahora la juventud, n 17, 2 de junio de 1983, p. 8. Citado por Manzano (2017). 
diantil de los años 60 y 70, asociado a la izquierda revolucionaria. Lo paradójico es que una parte de la propia izquierda de los 80 contribuyó al afianzamiento de esas ideas.

\section{La "primavera" y las nuevas tensiones politicas (1984-1985)}

Con la asunción de Raúl Alfonsín, el movimiento estudiantil cobró una centralidad pública novedosa y su presencia en los medios de prensa fue constante. El gobierno ubicaba a la juventud universitaria como un actor importante para la flamante democracia y, como vimos, buena parte de las agrupaciones estudiantiles también se autopercibian de esa manera. Por otra parte, la campaña radical se había apoyado en los sectores juveniles de la Coordinadora y la FM, que a la vez avanzaban en la universidad basados en el amplio optimismo que generaba la figura de Alfonsín (Altamirano, 1987). En efecto, el sector de FM que se había consolidado en la UBA estaba directamente vinculado con el alfonsinismo dentro de la UCR.

No obstante, con la asunción del gobierno radical aparecieron nuevas tensiones dentro de la Universidad, una de cuyas bases fue la fuerte ampliación de la matrícula (Buchbinder y Marquina, 2008). Seis días después de asumir, Alfonsín dispuso la normalización de la UBA con Francisco Delich como rector normalizador. El movimiento estudiantil esperaba una resolución favorable a sus reclamos en el marco de la restauración constitucional y uno de los temas más conflictivos fue sin dudas el problema del ingreso. Si bien Delich eliminó de entrada los aranceles y los cupos, en 1984 mantuvo el examen de ingreso. Según el propio Delich (2014: 38): "El Ministerio de Educación decidió, atinadamente, mantener el ingreso con exámenes restrictivos [...]. Nos daría tiempo para implementar un sistema que conciliara calidad con cantidad".

Esta continuidad de aspectos de la politica universitaria precedente generó la reacción inmediata de diversos sectores del movimiento estudiantil desatando manifestaciones por el ingreso irrestricto en Filosofia y Letras, Psicologia, Sociología y Medicina, con asambleas masivas y organización de cuerpos de delegados de aspirantes. En ese contexto, "FM era presionada doblemente. Por sus propias bases y las agrupaciones estudiantiles que la corrian por izquierda y le recordaban sus consignas de campaña y por los funcionarios de gobierno" (Beltrán, 2013: 213). Como había ocurrido en 1982-1983, la izquierda fue parte de quienes impulsaron las manifestaciones, con la diferencia de que ahora el radicalismo estaba en el gobierno. En Filosofia y Letras, por ejemplo, la izquierda desbordó a la conducción de FM. 
Otro caso interesante es el de Medicina donde las autoridades sostuvieron el 7 como nota mínima para aprobar el examen de ingreso, dejando a miles de aspirantes afuera. El conflicto se prolongó durante meses, con concentraciones de 1000 aspirantes y un petitorio con 2500 firmas. En junio, una asamblea de 350 no ingresantes resolvió radicalizar el conflicto dando comienzo a una huelga de hambre en el hall de la facultad, que tuvo cierta repercusión mediática. ${ }^{28}$ Entonces, FM y Sinapsis (independientes de derecha) impulsaron y aprobaron en la comisión directiva del CEM el levantamiento de la huelga, aunque 22 estudiantes sostuvieron la medida con apoyo de varias fuerzas de izquierda. FM justificó su voto considerando que la huelga era "una medida extrema no acorde con el tiempo político de unidad nacional que vive el país", y agregando que "dicha medida contiene un profundo carácter sectario y desmovilizante que lleva la reivindicación de muchos a la responsabilidad de unos pocos". ${ }^{29}$ Es relevante registrar la apelación al clima de "unidad nacional" como argumento para intervenir en un conflicto gremial universitario, junto a la crítica a la izquierda y a los estudiantes huelguistas como "sectarios". FADEP (peronistas) y JUI criticaron a FM pero aceptaron la decisión del CEM, "reafirmando nuestra vocación unitaria", ${ }^{0}$ mientras el FAUDI acusaba a FM de "pasar a ser vocero de las autoridades de la Facultad". ${ }^{31}$

En el resto de las facultades, las movilizaciones conquistaron recuperatorios y la reducción de la nota mínima para aprobar, llevando a una gran ampliación del número de ingresantes. Un volante de la Comisión de No Ingresantes de Medicina se quejaba de que "se nos otorgó un solo recuperatorio a diferencia de las facultades que tuvieron hasta recuperatorio de dicho recuperatorio (sic)" ${ }^{32}$ Es decir, en la mayoría de las facultades los estudiantes impusieron una buena cantidad de medidas ad hoc que desbordaron los márgenes del examen de ingreso. Como resultado, 43.572 alumnos ingresaron a la UBA, cuya matrícula creció un $40 \%$ en sólo un año. ${ }^{33}$

Buscando contener esta masividad, las autoridades de la UBA instauraron en 1985 el Ciclo Básico Común (CBC), que generó otros

28. Clarín, 25 de junio de 1984.

29. Volante de Franja Morada de la Facultad de Medicina, “¿Qué propone Franja Morada para un ingreso más justo?”, junio de 1984.

30. Volante firmado por FADEP, JUI y AEPU, "Sobre el ingreso en Medicina", junio de 1984.

31. Volante de FAUDI, “¿Para ser estudiante se necesita una huelga de hambre?”, junio de 1984.

32. Volante firmado por la Comisión de No Ingresantes a Medicina 1984, julio de 1984.

33. La Nación, 8 de mayo de 1984. 
problemas. ${ }^{34}$ Para casi 60.000 inscriptos se dispusieron sólo tres sedes, que contaban en total con escasas 65 aulas..$^{35} \mathrm{El}$ desborde evidente de las sedes forzó a la incorporación de nuevas, con condiciones más precarias aún. En el segundo cuatrimestre los alumnos de la nueva sede Avellaneda se quejaban porque el edificio ¡no tenía baños! ${ }^{16}$ La falta de presupuesto e infraestructura era innegable y un $40 \%$ de los ingresantes no logró superar el ciclo en su primer año.

No tardaron entonces en aparecer los reclamos: se constituyó un cuerpo de delegados intersedes del CBC y se realizaron sentadas y marchas, donde aparecian nuevamente las fuerzas de izquierda. El MAS participó en los cuerpos de delegados, mientras en Medicina el PCR impulsó la Lista Recuperación junto a estudiantes independientes del $\mathrm{CBC}$. La desorganización del CBC también generó críticas "por derecha" como las de UPAU, que proponía volver al examen de ingreso. De este modo, el CBC se impuso como forma de ingreso a la UBA en medio de fuertes polémicas.

Durante la normalización emergieron también otros conflictos en los que se manifestaron las tensiones entre la conducción radical de la UBA y las posiciones estudiantiles. Uno de ellos fue el tratamiento hacia los concursos aprobados por la dictadura, donde predominó la idea de las autoridades de "analizar caso por caso" frente al planteo estudiantil de anulación de todos los concursos. Otra discusión tuvo que ver con la composición de los cogobiernos universitarios, donde se impuso la distribución aún vigente en la que el claustro de profesores cuenta con el 50\% de los representantes en los Consejos Directivos. En definitiva, la normalización de la UBA aparece como un periodo más conflictivo que el que describen las memorias del entonces rector Delich (2014).

Al mismo tiempo, los debates universitarios se daban en paralelo y en interrelación con los de la realidad nacional. Uno de los ejes principales de polémica giró en torno a la situación económica. En 1984, el tibio forcejeo del gobierno radical frente al FMI sirvió de base para una marcha unitaria del MOJUPO contra las presiones de ese organismo.

34. La idea de un ciclo básico estaba contemplada desde el inicio de la normalización (Delich, 2014), pero se preveía un ciclo de 2 años. Los conflictos del año 1984 aceleraron su implementación y terminaron de delinear la forma que adoptó.

35. Clarin, 20 de marzo de 1985. Las sedes eran el subsuelo de Ciudad Universitaria (sede Ciudad), una ex fábrica en Villa Urquiza (sede Drago) y un edificio abandonado de la Municipalidad porteña (sede Paseo Colón). La inscripción también resultó caótica: se convocó a 18.000 ingresantes por día durante una semana de febrero en Ciudad Universitaria, que debieron realizar filas de tres horas para anotarse (Clarín, 19 de febrero de 1985).

36. "La falta de sanitarios los obliga a recurrir forzosamente a un bar cercano o a una estación de servicio próxima" (Clarín, 18 de julio de 1985). 
La "Marcha contra la dependencia", que reunió a 70.000 personas, defendía "una Argentina en democracia para la liberación contra la dependencia", ${ }^{37}$ frase que sintetiza con precisión la pretensión de una parte de las fuerzas juveniles de los 80 de combinar los discursos de la liberación y los de la democracia. Sin formar parte de la convocatoria, asistieron también las juventudes del MAS, el PO y el PCR.

No obstante, cuando en 1985 Alfonsín reemplazó al Ministro de Economía Bernando Grinspun por Juan Vital Sourrouille y lanzó el paquete de medidas de ajuste conocido como Plan Austral, las tensiones dentro del MOJUPO comenzaron a hacerse más evidentes y la unidad entre sectores de la izquierda y FM cada vez más dificiles (Larrondo y Cozachcow, 2017). A la vez, crecieron las movilizaciones de la CGT encabezada por Ubaldini, frente a las que la FUBA tuvo una posición ambivalente, participando de algunas convocatorias y de otras no. En ningún caso se registró una confluencia obrero-estudiantil masiva.

Las medidas de ajuste también repercutieron dentro de las universidades, dando lugar a paros de los no docentes y los docentes universitarios. De este modo, se fue delineando un nuevo eje de reivindicación, específico del período abierto en 1983: el reclamo por aumento de presupuesto, apoyado en el hecho de que "el costo del crecimiento de la matrícula [...] fue compensado, principalmente, por los docentes y empleados administrativos, cuyos salarios disminuyeron de manera constante" (Buchbinder, 2005: 218).

También en relación a la cuestión de los DDHH, emergieron nuevas contradicciones en la medida en que los organismos profundizaron sus reclamos al gobierno, acompañados entre otros por las agrupaciones independientes de izquierda de la UBA, que establecieron un vínculo cercano con ellos. Hacia 1985, los pocos temas en los que se mantuvo la unidad de varias fuerzas de izquierda, el peronismo y el radicalismo fueron los de la situación internacional. El apoyo al sandinismo en Nicaragua, la denuncia de la dictadura de Pinochet en Chile y la solidaridad con Cuba fueron una constante de estos años.

\section{Las primeras elecciones de centros con Alfonsin en el gobierno}

En el marco de todas las tensiones planteadas anteriormente, en las elecciones de centros de estudiantes de 1984, FM mantuvo la hegemonía pero sufrió un retroceso: perdió algunos centros y cayó del $40 \%$ al $32 \%$ de los votos totales. La agrupación que logró canalizar un descontento relativo con Franja fue la JUI, que se alzó con la conducción de cuatro centros y más del $20 \%$ de los votos totales (Tablas 3 y 4 ).

37. Clarín, 23 de junio de 1984. 
Tabla 3. Conducciones de centros de estudiantes de la UBA (1984-1985).

\begin{tabular}{|l|c|c|}
\hline Centro & $\mathbf{1 9 8 4}$ & $\mathbf{1 9 8 5}$ \\
\hline Agronomía & LAI (ind. der.) & LAI (ind. der.) \\
\hline Arquitectura & FM & FM \\
\hline Ciencias Económicas & FM & FM \\
\hline Ciencias Exactas y Naturales & JUI & AEI (ind. izq.) \\
\hline Derecho & FM & FM \\
\hline Farmacia y Bioquímica & FM & FM \\
\hline Filosofía y Letras & JUI & JUI + JUP-C \\
\hline Ingeniería & Quantum (ind. der.) & FM \\
\hline Medicina & FM & FM \\
\hline Odontología & FM & FM \\
\hline Psicología & JUI & JUI \\
\hline Sociología & JUI & PC + MAS + JUP-R \\
\hline Veterinaria & Gestar (ind. izq.) & Gestar + PC + JUP-R \\
\hline
\end{tabular}

De un lado, esta elección señalaba un relativo "giro a la izquierda" de una parte del estudiantado porteño, en el marco de los conflictos detallados más arriba. Pero a la vez, esos votos se encauzaban hacia una forma muy particular de la izquierda de los 80 . La JUI combinaba un discurso latinoamericanista y de liberación con la imagen de una fuerza "nueva" e inscripta dentro de los valores democráticos. ${ }^{38}$ De este modo, su avance podría interpretarse como un voto crítico que pretendía apuntalar por izquierda a la UCR, tratando de impulsar políticas más avanzadas sin romper necesariamente con el partido de gobierno. ${ }^{39}$

Posteriormente, en las elecciones de 1985, FM mantuvo su dirección y el PI sostuvo valores cercanos al $20 \%$. Pero ese año la JUI perdió dos centros: Ciencias Exactas y Naturales, frente a los independientes de izquierda de AEI, y Sociologia frente a la alianza del PC, el MAS y un sector del peronismo. El avance de AEI en Ciencias Exactas y Naturales expresaba cierto cuestionamiento a la lógica de partidos imperante en

38. Los jóvenes del PI eran retratados por varios cronistas de la época como "psicobolches", figura con la que satirizaban a una parte de los militantes de izquierda de los 80 como "meros consumidores de una estética revolucionaria" (Manzano, 2017). 39. En 1984, la JUI volvió a constituir un frente con FM en el Congreso de la FUBA, obteniendo la Secretaría General. No obstante, podría pensarse en un acuerdo técnico en la medida en que ambas fuerzas no presentaron ninguna lista conjunta en las facultades. 
Tabla 4. Total de votos UBA, elecciones centros de estudiantes 1983-1985.

\begin{tabular}{|l|r|r|c|}
\hline Agrupación & $\mathbf{1 9 8 3}$ & $\mathbf{1 9 8 4}$ & $\mathbf{1 9 8 5}$ \\
\hline JUI-PI & $9,1 \%$ & $21,0 \%$ & $20,2 \%$ \\
\hline BUIT & $7,6 \%$ & $5,5 \%$ & $3,9 \%$ \\
\hline MOR-FJC-PC & $5,7 \%$ & $6,1 \%$ & $7,9 \%^{*}$ \\
\hline MAS & $2,0 \%$ & $1,9 \%$ & \\
\hline UJS-PO & $1,0 \%$ & $0,5 \%$ & $0,4 \%$ \\
\hline FAUDI-PCR & $0,3 \%$ & $0,2 \%$ & $0,6 \%$ \\
\hline FM & $40,3 \%$ & $32,5 \%$ & $31,7 \%$ \\
\hline UPAU & $1,0 \%$ & $6,8 \%$ & $15,3 \%$ \\
\hline
\end{tabular}

* En 1985 constituyeron el frente FELNA junto a la JUP-Regional

la militancia de los $80 .{ }^{40}$ Por su parte, la FJC había virado de una lógica de mayores acuerdos con FM a la unidad con el MAS y un sector del peronismo. ${ }^{41}$ En ese contexto, la JUI también tomó mayor distancia de FM, reforzando su alianza con el peronismo renovador. Finalmente, en facultades como Derecho o Ingeniería, crecía la influencia de la derecha con UPAU (Tablas 3 y 4).

En este marco, a inicios de 1986, la elección de Oscar Shuberoff como Rector consolidó las posiciones de FM en las estructuras de gobierno universitario pero también su aislamiento. El Congreso de la FUBA no se pudo realizar ya que Franja no logró que otras fuerzas dieran quórum. La unidad que se había producido en 1983 ahora se desvanecía, con criticas de gran parte del resto de las agrupaciones a la política económica del alfonsinismo.

40. Un graffiti en Ciudad Universitaria parodiaba la fórmula de las agrupaciones universitarias partidarias: "AEI es la expresión universitaria de sus integrantes" (Clarin, 21 de octubre de 1985).

41. El "giro" del PC fue una de las expresiones de la profunda crisis interna que vivió ese partido en la posdictadura (Casola, 2014). Una parte creciente de los militantes criticaba el apoyo que había brindado el PC a Videla, así como el retiro de las candidaturas propias en las elecciones de 1983 para acompañar al PJ. En ese contexto, la dirección del PC impulsó un "viraje revolucionario" que culminó en el XVI Congreso de 1986, alimentado por las ilusiones que generaban procesos como el de Nicaragua a nivel latinoamericano. Aunque, como señala Casola, el "viraje" en realidad fue limitado, una de sus consecuencias fue el cambio en el marco de alianzas del PC hacia fuerzas como el MAS. 


\section{A modo de cierre}

En los últimos años de la dictadura se vivió un auge de las movilizaciones estudiantiles en contra de la politica universitaria vigente y del régimen en general. El ciclo de protestas iniciado en 1982 se extendió durante los primeros dos años del gobierno de Raúl Alfonsín en reclamo del cumplimiento de reivindicaciones como el ingreso irrestricto. En las distintas etapas de este ciclo, las agrupaciones de izquierda de la UBA intervinieron de forma sostenida, tanto en las manifestaciones como en la reorganización de los centros de estudiantes. El despliegue de la militancia juvenil que caracterizó la salida de la dictadura también impactó en el crecimiento de varias de estas fuerzas, muchas de las cuales contaban con un caudal de militantes significativo dentro de las facultades.

Al mismo tiempo, las primeras elecciones de centros de estudiantes dieron cuenta de importantes cambios políticos, con la hegemonía de FM y el retroceso del peronismo, el PC, el trotskismo y el maoísmo. Dentro de la izquierda, lograron avanzar fuerzas nuevas como el PI y los independientes, con escasa o reciente tradición de militancia en las facultades. FM se presentaba como la superación de la "violencia del pasado", absorbiendo ciertas consignas antiimperialistas y de derechos humanos en un nuevo marco de ideas dominantes que tenían como centro la consolidación de la democracia. Buena parte de las fuerzas de izquierda hizo propios estos nuevos sentidos y valores e incluso estableció marcos de alianza estudiantil con la agrupación radical, como se expresó en la conformación del MOJUPO y en la lista que triunfó en el primer congreso de la FUBA en 1983.

Los primeros años del mandato de Alfonsín definieron un nuevo escenario marcado por la tensión entre las expectativas de gran parte de los estudiantes con el nuevo gobierno y las políticas que el mismo fue llevando, tanto en materia universitaria como a nivel económico. Movilizaciones estudiantiles cuestionaron la continuidad del examen del ingreso en 1984 y las precarias condiciones de cursada del CBC en 1985. Hacia fines de ese año crecieron las críticas hacia el radicalismo por parte de distintos afluentes de la izquierda y se produjeron reacomodamientos en las alianzas estudiantiles.

Mirado de conjunto, el período tiene como una de sus particularidades más notables el surgimiento y consolidación de la democracia como nuevo horizonte político ideológico, como supuesto garante y camino para cualquier transformación social. Este eje sirvió también como aglutinador de alianzas entre las juventudes de partidos políticos y las agrupaciones estudiantiles a la salida de la dictadura. Cabe señalar que la democracia, en el sentido que se la entendió en los 80 , 
no era un valor importante para los militantes de los 60 y 70 , que más bien desconfiaban de los alcances de esa consigna. Para las fuerzas de izquierda este cambio supuso una clara dificultad en la medida en que las nuevas ideas se consolidaron por contraste con los proyectos revolucionarios de las décadas anteriores. La reconversión de una parte de la izquierda hacia los nuevos valores hegemónicos no evitó que se la asociara en muchos casos con el pasado que se pretendia superar.

Aun en este dificil contexto, las fuerzas de izquierda mantuvieron su militancia y fueron parte activa de las movilizaciones estudiantiles de la etapa. Se destaca la continuidad de algunas de las demandas de los estudiantes entre el final de la dictadura y el inicio de la democracia, al tiempo que emergieron otras nuevas, como el reclamo por aumento del presupuesto. En este sentido, en la medida en que el radicalismo se consolidó como gobierno universitario, el papel de la izquierda fue importante en el sostenimiento de las reivindicaciones estudiantiles y colaboró en que la asunción del gobierno radical no representara el congelamiento de los reclamos del movimiento estudiantil.

\section{Referencias bibliográficas}

Aboy Carlés, Gerardo (2001), Las dos fronteras de la democracia argentina, Rosario: Homo Sapiens.

Altamirano, Carlos (1987), "La Coordinadora: elementos para una interpretación", en José Nun y Juan Carlos Portantiero (comps.), Ensayos sobre la transición democrática en la Argentina, Buenos aires: Puntosur, pp. 295-332.

Beltrán, Mónica (2013), La Franja. De la experiencia universitaria al desafio del poder, Buenos Aires: Aguilar.

Blanco, Rafael y Pablo Vommaro (2017), "Otros caminos, otros destinos: transformaciones en los espacios y prácticas cotidianas de participación juvenil en los años ochenta", en Melina Vázquez et al. (comps.), Militancias juveniles en la Argentina democrática, Buenos Aires: Imago Mundi, pp. 1-25.

Buchbinder, Pablo (2005), Historia de las universidades argentinas, Buenos Aires: Sudamericana.

- (2014), "La Universidad y el tercer peronismo: notas sobre el debate parlamentario en torno a la Ley Taiana" en Mariano Millán (comp.), Universidad, politica y movimiento estudiantil en Argentina, entre la "Revolución Libertadora" y la democracia del 83, Buenos Aires: Final Abierto, pp. 183-201.

Buchbinder, Pablo y Mónica Marquina (2008), Masividad, heterogeneidad y fragmentación: el sistema universitario argentino, 1983-2008, Buenos Aires: UNGS-Biblioteca Nacional. 
Canelo, Paula (2009), El proceso en su laberinto. La interna militar de Videla a Bignone, Buenos Aires: Prometeo.

Casola, Natalia (2014), "De la "convergencia cívico-militar" al "viraje revolucionario". La crisis del Partido Comunista durante los años 80", en Archivos de Historia del Movimiento Obrero y la Izquierda, $\mathrm{n}^{\circ} 5$, Buenos Aires, pp. 51-70.

- (2015), El PC argentino y la dictadura militar. Militancia, estrategia politica y represión estatal, Buenos Aires: Imago Mundi.

Cristal, Yann (2015), "Las primeras elecciones de los centros de estudiantes de la UBA tras la proscripción de la dictadura (1982-1983)", en Cuaderno $n^{\circ}$ 6, Programa Historia y Memoria de la Universidad de Buenos Aires, Buenos Aires. Disponible en: http://www.uba.ar/historia/contenidos. php?id $=6 \& s=57$.

- (2017), "El movimiento estudiantil de la Universidad de Buenos Aires en el final de la última dictadura (1982-1983)", en Sociohistórica, vol. 40, La Plata. Disponible en: https://doi.org/10.24215/18521606e031.

Delich, Francisco (2014), 808 dias en la Universidad de Buenos Aires, Buenos Aires: Eudeba.

Franco, Marina (2015), "La "teoría de los dos demonios" en la primera etapa de la posdictadura", en Claudia Feld y Marina Franco (dirs.), Democracia, hora cero. Actores, politicas y debates en los inicios de la posdictadura, Buenos Aires: Fondo de Cultura Económica, pp. 23-80.

Friedemann, Sergio (2016), La Universidad Nacional y Popular de Buenos Aires (1973-1974). Una reforma universitaria inconclusa, tesis doctoral, Facultad de Ciencia Sociales, Universidad de Buenos Aires, inédita.

Gilbert, Isidoro (2009), La Fede. Alistándose para la revolución. La Federación Juvenil Comunista, 1921-2005, Buenos Aires: Sudamericana.

Larrondo, Marina y Alejandro Cozachcow (2017), "Un llamado a la unidad: la experiencia del Movimiento de Juventudes Politicas (MOJUPO) en la transición a la democracia”, en Melina Vázquez et al. (comps), Militancias juveniles en la Argentina democrática, Buenos Aires: Imago Mundi, pp. 51-71.

Lesgart, Cecilia (2002), "Usos de la transición a la democracia. Ensayo, ciencia y política en la década del ochenta", en Estudios Sociales, $\mathrm{n}^{\circ}$ 22-23, pp. 163-185.

Luciani, Laura (2017), Juventud en dictadura: representaciones, politicas y experiencias juveniles en Rosario: 1976-1983, La Plata: UNLP-UNAM-UNGS.

Manzano, Valeria (2017), "Para entender el psicobolchismo: juventud, cultura y politica en la Argentina de la década de 1980", en XVI Jornadas Interescuelas de Historia, Mar del Plata.

Millán, Mariano (2015), "Franja Morada en la Universidad de Buenos Aires (1973-1976)", en VI Congreso Regional de Historia e Historiografia, Santa Fe.

Muiño, Oscar (2011), Los dias de la Coordinadora: politica, ideas, medios y sociedad: 1968-1983, Buenos Aires: IML-Corregidor. 
Pedrosa, Fernando (2002), "La universidad y los estudiantes frente a la dictadura militar", en Renate Marsiske (coord.), Movimientos estudiantiles en la historia de América Latina, México: UNAM.

Perel, Pablo, Eduardo Raíces y Martín Perel (2006), Universidad y dictadura. Derecho, entre la liberación y el orden (1973-1983), Buenos Aires: Ediciones del CCC.

Polak, Laura y Juan Carlos Gorbier (1994), El movimiento estudiantil argentino (Franja Morada, 1976-1986), Buenos Aires: CEAL.

Seia, Guadalupe (2015), "Reconfiguraciones de la vida estudiantil durante la última dictadura. Apuntes sobre los casos de las Facultades de Filosofía y Letras y Ciencias Exactas y Naturales de la Universidad de Buenos Aires (1976-1981)", en Revista Binacional Brasil-Argentina, vol. 4, n 1. Disponible en: http://periodicos.uesb.br/index.php/rbba/issue/current.

- (2016), "Militancia, oposición y resistencia estudiantil en la Universidad de Buenos Aires durante la etapa final de la última dictadura (19811983)", en Historia, Voces y Memoria, n 10, Buenos Aires. Disponible en: http://revistascientificas.filo.uba.ar/index.php/HVM/article/view/3379.

- (2017), "La búsqueda por la institucionalización y "normalización universitaria" de la última dictadura en Argentina. Ley universitaria, nuevo estatuto y concursos docentes en el caso de la Universidad de Buenos Aires (1980-1983)", en Debate Universitario, vol. 6, n 10, julio, Buenos Aires. Disponible en: http://portalreviscien.uai.edu.ar/ojs/index.php/ debate-universitario/article/view/ 106.

Toer, Mario (1988), El movimiento estudiantil de Perón a Alfonsin (1946-1986), vol. 2, Buenos Aires: CEAL.

$* * *$

Titulo: The student left of the University of Buenos Aires in the democratic transition (1982-1985)

Resumen: En este trabajo examinamos el desarrollo de las agrupaciones estudiantiles de izquierda de la Universidad de Buenos Aires (UBA) entre el final de la última dictadura y los inicios del gobierno de Raúl Alfonsín. Por un lado, analizamos su papel en la reorganización de los centros de estudiantes y en las movilizaciones universitarias de esos años. Por otro, consideramos las dificultades que enfrentaron en el complejo escenario de los 80, caracterizado por fuertes cambios políticos, entre los que se destacan la nueva hegemonía de Franja Morada sobre el movimiento estudiantil porteño y la relativa pérdida de influencia de la izquierda. Para su desarrollo hemos triangulado fuentes orales producto de entrevistas en profundidad realizada por los autores, una variedad de fuentes documentales (oficiales, prensa, materiales de agrupaciones estudiantiles, periódicos partidarios, entre otros) y diversos trabajos académicos sobre la etapa. Palabras clave: movimiento estudiantil - Universidad de Buenos Aires - izquierda - transición democrática 


\begin{abstract}
In this paper we examine the development of the student groups of the left at the University of Buenos Aires (UBA) between the end of the last dictatorship and the beginning of the government of Raúl Alfonsin. On the one hand, we analyze their role in the reorganization of the student centers and the university mobilizations of those years. On the other hand, we consider the difficulties they faced in the complex scenario of the 1980s, characterized by strong political changes, among which the new hegemony of Franja Morada over the Buenos Aires student movement and the relative loss of left influence. For its development we have triangulated oral sources product of in-depth interviews carried out by the authors, a variety of documentary sources (official, press, materials of student groups, political newspapers, among others) and various academic works.
\end{abstract}

Key words: student movement - University of Buenos Aires - left - democratic transition

Recepción: 18 de enero de 2018. Aprobación: 27 de febrero de 2018. 